\title{
Grupos de convivência: uma experiência de intervenções multiprofissionais para prevenção e promoção da saúde na Atenção Básica, uma parceria da Estratégia Saúde da Família e do Núcleo de Apoio à Saúde da Família no município de Viçosa/MG
}

Nicole Donato Viana, Isabelle Abranches da Silva, Élita Marina Ramos Soares, Yndiara Aparecida Moreira Rodrigues, Pauliana Pimentel Coelho Garcia

\section{Resumo}

O NASF consiste em uma equipe composta por profissionais diferentes da área da saúde que visem a ampliação, apoio e aperfeiçoamento da gestão no atendimento da Atenção Primária à Saúde (APS) aos usuários das unidades referentes. A finalidade geral do NASF é observar e perceber o paciente como indivíduo inserido num meio com aspectos que podem ser analisados pelos profissionais envolvidos na demanda afim da resolutividade do problema identificado. No presente trabalho buscamos relatar uma experiência de prevenção e promoção da saúde construída a partir de grupos de convivência intermediados pela equipe multiprofissional do NASF aos usuários pertencentes à área de abrangência da ESF Bom Jesus de Viçosa/MG. Para a elaboração da proposta de trabalho, foram realizadas as etapas: foram executadas três etapas: diagnóstico situacional, revisão bibliográfica e elaboração do plano de ação. Inicialmente, realizou-se um diagnóstico situacional da área de abrangência da ESF Bom Jesus com o objetivo de identificar os principais problemas. $\mathrm{O}$ diagnóstico situacional foi baseado no método de estimativa rápida participativa, que constitui um modo de se obter informações sobre um conjunto de problemas e dos recursos potenciais para o seu enfrentamento, num curto período de tempo e sem altos gastos. Foram pesquisados autores relacionando: doenças crônicas, equipe multidisciplinar, grupo de convivência, plano de intervenção, prevenção. Foi elaborado um plano de ação e já iniciado no intuito de alcançar o objetivo proposto. Os grupos de convivência iniciaram em julho de 2015 com frequência mensal e agenda/ações/atividades pré-estabelecidas com atuações de todos os profissionais do NASF (Assistente Social, Farmacêutica, Fisioterapeuta, Nutricionista, Profissional de Educação Física, Psicóloga). Optou-se por trabalhar a com a metodologia significativa (rodas de conversa, dinâmicas e atividades), explorando como temas de discussão: qualidade de vida, autoestima, troca de saberes/experiências, motivação e socialização. Conseguimos abordar os pacientes participantes e foi possível identificar por relatos que esses encontros: propiciaram a ampliação da consciência dos pacientes em relação a temas e à adoção de comportamentos promotores de saúde; promoveram a socialização e o troca de saberes técnicos e populares; melhoraram a autonomia dos participantes e sua corresponsabilização no cuidado integral à saúde; e desmistificaram crenças populares ligadas à saúde. Essa experiência possibilitou uma visão mais ampliada da prática interdisciplinar e a percepção da educação em saúde, através de grupos de convivência podemos contribuir para melhorar a qualidade de vida de pessoas com doenças crônicas não transmissíveis por meio da prevenção e promoção de saúde.

Descritores: Grupos de convivência; Trabalho Interdisciplinar; Saúde da Família. 